Department of Physiology,

Fac. Vet. Med., Suez Canal University, Ismailia, Egypt.

\title{
BEHAVIORAL AND PHYSIOLOGICAL INFLUENCES OF LISTENING SLOW AND FAST MUSIC ON MILKING BUFFALOES
}

(With 4 Tables, 2 Figures and One Plate)

By

\section{S.M.M. ABUZEAD and A.M. KHALIL*}

* Animal Hygiene, Zoonoses \& Animal Behavior, Fac. Vet. Med.,

Suez Canal University, Ismailia, Egypt.

(Received at 20/6/2007)

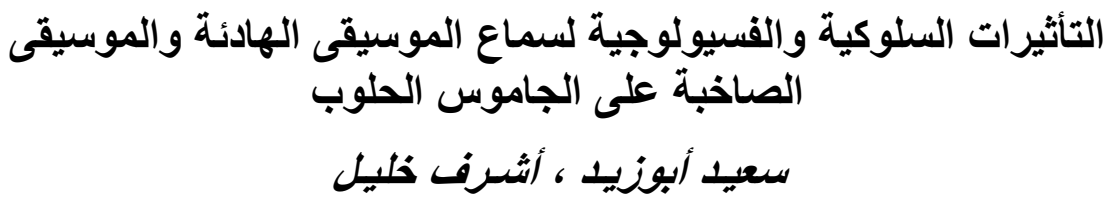

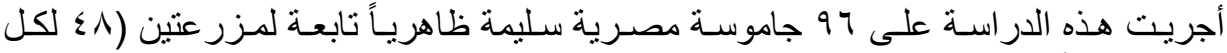

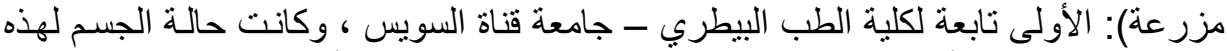

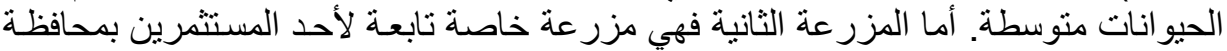

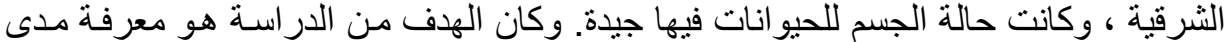

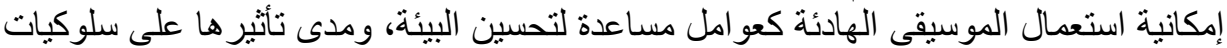

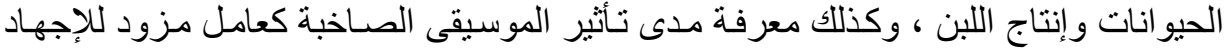

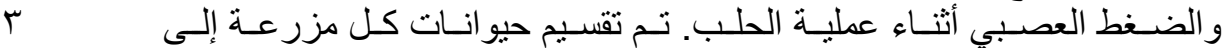

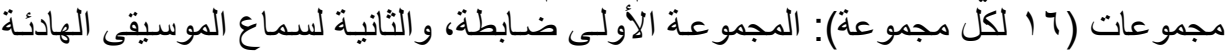

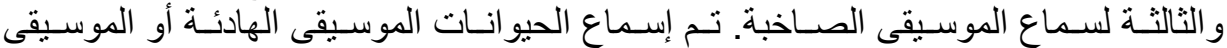

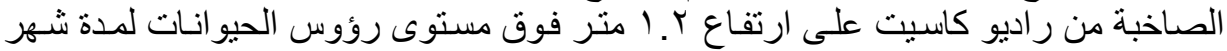

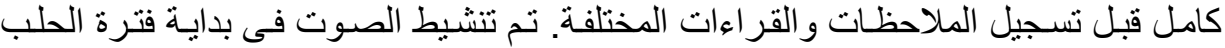

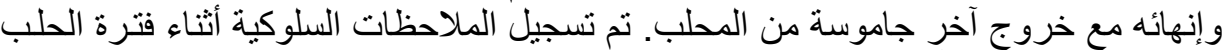

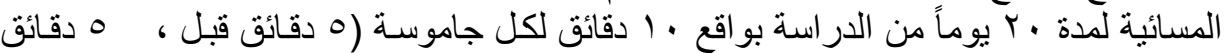

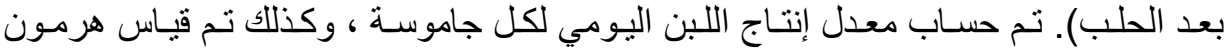

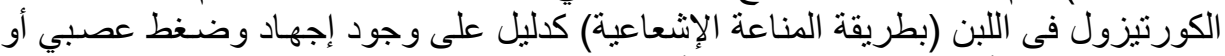

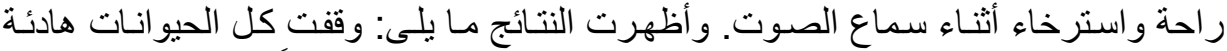

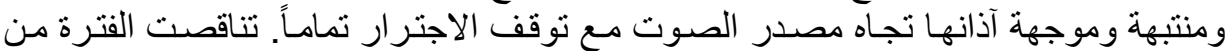

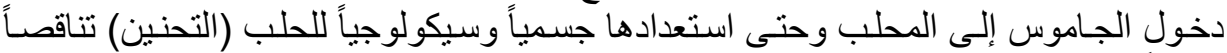

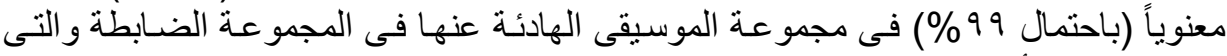

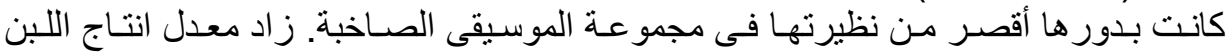

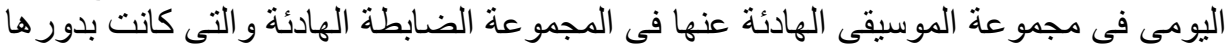

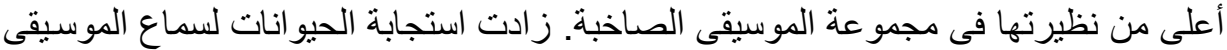

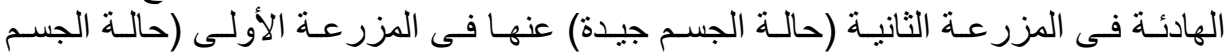




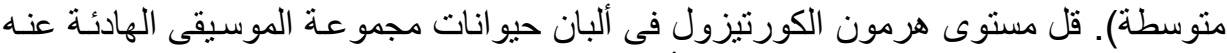

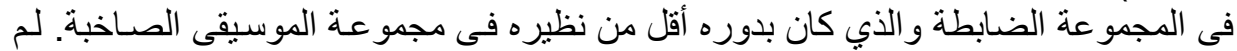

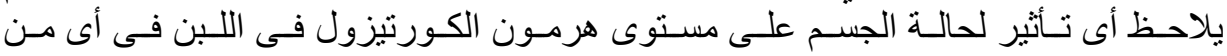

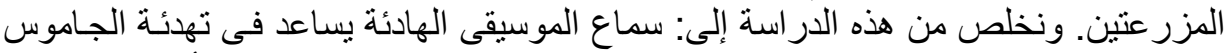

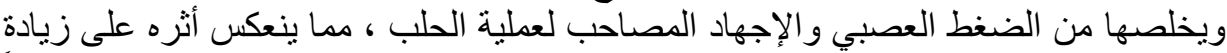

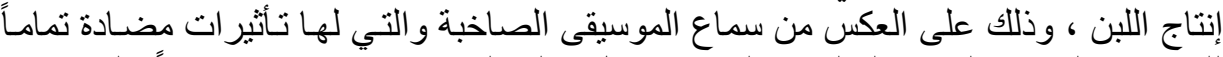

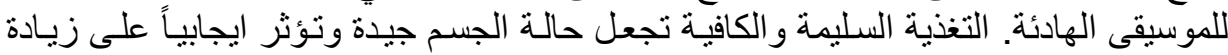

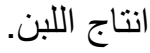

\section{SUMMARY}

The present study was carried out on 96 apparently healthy pluriparous buffalo cows with two levels of body condition score (BCS), moderate and high (48 each). The aim was directed to study the influence of listening slow and fast music as well as the effect of BCS on the behavior, daily milk yield and milk cortisol level. Inside BCS level, 48 buffalo cows were divided into 3 groups (16 each). The $1^{\text {st }}$ group was left as control while the $2^{\text {nd }}$ and $3^{\text {rd }}$ groups were assigned for listening slow and fast music, respectively. Listening of sounds was carried out for one month before recording our observations. The sounds were activated at the start of milking period and terminated after the last buffalo cow has left the milking parlor. Behavioral observation and daily milk yield were recorded and milk samples were collected for estimation of cortisol using RIA. The study revealed that presenting of sounds (slow music or fast music) to buffalo cows resulted in standing still attentively without rumination and directing the ears toward the sound source. The latency (minutes) for buffalo cows from beginning of handling the teats till being psychologically and physically prepared to milking reduced significantly $(\mathrm{P}<0.01)$ in the slow music group than the other groups. Daily milk yield of buffalo cows increased significantly $(\mathrm{P}<0.01)$ in slow music group than that of the control group, while decreased significantly in fast music group. The increase of daily milk yield in slow music group was more significant $(\mathrm{P}<0.01)$ in animals having high BCS than those with moderate BCS. Milk cortisol of buffalo cows in slow music group was significantly $(\mathrm{P}<0.05)$ lower than that in fast music and control groups $(\mathrm{P}<0.05)$. There were no significant differences in milk cortisol level between moderate and high BCS groups after listening either slow music or fast music. We concluded that listening of slow music as an environmental enrichment had the effect of alleviating stress and relaxing the animals which resulted in greater milk yields. 
Key words: Slow music, fast music, body condition, buffalo cows, behavior, milk yield, cortisol.

\section{INTRODUCTION}

Buffaloes are of great agricultural importance in Egypt and all developing countries in view of the fact that they provide meat and dairy product. Environmental enrichment is a popular goal of research in the field of applied ethology. Environmental enrichment is defined as an improvement in the biological functioning of captive animals resulting from modifications of their environment. There is a considerable evidence that environmental enrichment results in marked behavioural and physiological effects on mammals (Greenough, 1976 and Anonymous, 1994). Uetake et al. (1997) reported a stimulatory effect of music on the voluntary approach of dairy cows to an automatic milking system.

On the other hand, Noise is a potential stressor to animals and has an important psychological component, it is a potential source of fear for animals. Algers et al. (1978) reported a significant negative impact of continuous noise on animal health. It has been shown that noise is a stressor in cattle (Forsling et al., 1984; Elridge, 1988; Francesco et al., 1990; Arave et al., 1991; Grandin, 1996 and Waynert et al., 1999). Soothing noise is stimulating and relaxing for cows which caused them to increase their milk production (McCowan, et al., 2002).

Researchers tried to relieve the stress of noise by using of music. Over the years, music has been used successfully to reduce pain, depression, stress and anxiety (McCaffrey and Good, 2000; Hilliard, 2001 and Vickers and Cassileth, 2001), and is widely employed in institutional settings as an alternative form of therapy (Lipe, 1987 and Christie, 1992). It has been found that slow music increased daily milk yield in cows by $3 \%$ while fast music decreased it by $2 \%$ (Nold, 2007).

An increase in hypothalamic-pituitary-adrenocortical activity indicates a physiological response to different stressors, and measurement of plasma corticosteroids is frequently used to study stress response (Sapolsky et al., 2000; Pacak and Palkovits, 2001). However, blood sampling itself is disturbing and the use of previous catheterization to minimize this disturbance is not always possible (Cook et al., 1996). Consequently, there is an interest in measuring corticosteroid concentrations in other body fluids, which would result in minimal stress (Möstl and Palme, 2002). On the contrary, milk samples can be easily taken at fixed time intervals before and after an imposed 
stress. For these reasons, interest in the measurement of milk cortisol concentrations has increased and has been used to assess stress reactions in cattle (Gygax et al., 2006). Milk cortisol level was reported to be $0.35 \pm 0.06 \mathrm{ng} / \mathrm{ml}$ in cows under normal management condition (Shutt and Fell, 1985).

The purpose of the present study was to examine of the influence of providing Egyptian buffaloes with slow music and fast music on the behavior, daily milk yield and milk cortisol. Moreover, the study was directed to examine the effect of body condition score on the response of buffalo cows to listening of slow music and fast music.

\section{MATERIALS and METHODS}

\section{Animals:}

This study was carried out on 96 apparently healthy pluriparous buffalo cows belonging to two farms. The first one (48 buffalo cows of moderate body condition score) belongs to the Faculty of Veterinary Medicine, Suez Canal University, Ismailia, Egypt. The second farm (48 buffalo cows of high body condition score) is a private farm located in El-Sharkia, Egypt. The age of the animals ranged from 5- 8 years old. All the animals had normal parturition and puerperium passed normally. Scoring body condition of buffalo cows was done according to the method reported in cattle by Spitzer (1986).

\section{Management programs:}

Animals were housed in a loose-housing yard that was compatible with labor saving and comfort of animals. Water was add ad libtium to animals throughout the day. Buffalo cows of the first farm were fed $3 \mathrm{~kg}$ concentrate mixture $+4 \mathrm{~kg}$ green corn $+2 \mathrm{~kg}$ wheat or rice straw per head per day. Mineral mixture was available in the form of 20-40 g calcium carbonate (ground limestone) +40 gm common salt per head per day. Feeding of animals in the second farm was the same as that of the first one except the amount of the concentrate mixture which was $6 \mathrm{~kg}$ and green corn which was $6 \mathrm{~kg}$ per head per day. All animals were milked twice daily at 6 a.m. and 6 p.m.

\section{Experimental protocol:}

In the first farm: 48 buffalo cows of moderate body condition score were divided into 3 groups (16 each). The first group was assigned as control (no listening to either slow music or fast music). The second group was assigned for listening of slow music. The third group was assigned for listening of fast music. In the second farm: 48 buffaloes of 
high body condition score were divided into 3 groups (16 each) like the first farm. Listening of sounds (slow music or fast music) was carried out for one month before observation and recording. Slow music or fast music were played during the milking period by using a cassette player located approximately $1.2 \mathrm{~m}$ above the head of the milking buffalo cows. The sounds were activated in both farms at the start of each milking period and terminated after the last milking buffalo cows has left the milking parlor. Behavioral observation were recorded for one week following the listening period. The daily milk yield per buffalo cow was recorded during the whole period of the experiment.

\section{Observations and records:}

Behavioral observations were done through one corner of the milking parlor and the relevant behavioral activities including rumination, posture and evidences of responses to the listening either slow music or fast music were observed carefully according to Paul and Patrick (1986). Accordingly the percentage of animals that showed the above mentioned behavioral activities were studied in comparison with the control group. The latency (in minutes) for buffalo cows from entering of the parlor till being physically and psychologically prepared for milking was studied during presenting the slow music or fast music and under control conditions. Further, the number of buffalo cows that showed some nervous manifestations (kicking and refusing handling and milking) was also recorded before and after presenting the slow music or fast music. All buffalo cows in the parlor were recorded for 10 minutes from entering the milking parlor. Three buffalo cows were selected randomly from each group for recording the behavioral parameters each day and recording all animals continued for one week.

\section{Milk sampling}

Milk samples were collected from all groups for cortisol determination. Concerning the listening groups, milk samples were collected from the buffalo cows during playing the slow music and fast music. Milk cortisol was extracted using diethyl ether and stored at- $20^{\circ} \mathrm{C}$ until analyzed using radioimmunoassay kits (Diagnostic systems laboratories, INC., Webster, Texsas, USA) according to Shutt and Fell, 1985.

\section{Statistical analysis}

Data were Statistical analyzed by using Chi-square, analysis of variance (ANOVA) and Least significant difference (LSD) using MINITAB (1992). 


\section{RESULTS}

Table 1: Behavioral activities of buffalo cows during presenting the slow music and Holy Qur'an during milking.

\begin{tabular}{|c|c|c|c|}
\hline Behavioral activities & $\begin{array}{l}\text { Control } \\
\text { group }\end{array}$ & $\begin{array}{l}\text { Slow } \\
\text { music } \\
\text { group }\end{array}$ & $\begin{array}{l}\text { Fast } \\
\text { music } \\
\text { group }\end{array}$ \\
\hline $\begin{array}{l}\text { 1)Rumination (\%) } \\
\text { 2)Standing still with attention }(\%) \\
\text { 3) Orientation of ears toward the sound source }(\%) \\
\text { 4)Latency (minutes) for buffalo cows from } \\
\text { beginning of handling the teats till being } \\
\text { physically prepared to milking }\end{array}$ & $\begin{array}{c}7.1 \pm 1.32 \%^{\mathrm{a}} \\
0 \%^{\mathrm{a}} \\
0 \%^{\mathrm{a}} \\
4.3 \pm 1.3^{\mathrm{a}}\end{array}$ & $\begin{array}{l}0.0 \%^{\mathrm{b}} \\
100 \%^{\mathrm{b}} \\
100 \%^{\mathrm{b}} \\
2.4 \pm 1.0^{\mathrm{b}}\end{array}$ & $\begin{array}{c}0.0 \%^{\mathrm{b}} \\
100 \%^{\mathrm{b}} \\
100 \%^{\mathrm{b}} \\
5.8 \pm 0.81^{\mathrm{c}}\end{array}$ \\
\hline
\end{tabular}

Values carrying different superscripts in the same row are significantly different $(\mathrm{P}<0.01)$.

From Table 1: it appears that presenting of sounds (slow music or fast music) to buffalo cows resulted in standing still attentively without rumination and directing the ears toward the sound source (Plat 1). In addition, the mean latency (minutes) for buffalo cows from beginning of handling the teats till being psychologically and physically prepared to milking reduced significantly $(\mathrm{P}<0.01)$ from $4.3 \pm 1.3$ in the control group to become $2.4 \pm 1.0$ in the slow music group and increased significantly $(\mathrm{P}<0.05)$ in fast music group.

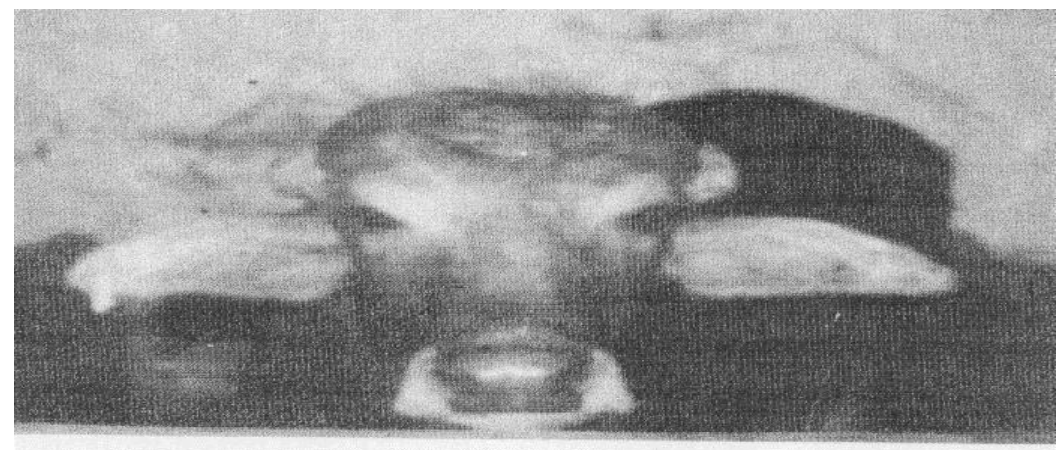

Plate 1: A buffalo cow is standing still attentively and directing the ears toward the sound source

Moreover, we found that there were some buffalo cows in each group hardly manipulated and thus refused milking. After listening of slow music some of these cases responded and easily manipulated by the milker (Table 2). On the other hand, all of other cases in control and fast 
music groups were still hardly manipulated by the milker during the whole period of the current study.

Table 2: Influence of listening slow music or fast music in relieving hard manipulation in buffalo cows.

\begin{tabular}{|c|c|c|c|}
\hline & Control & Slow music & Fast music \\
\hline Responded & $0 / 3^{* *}$ & $2 / 5^{*}$ & $0 / 4^{* *}$ \\
\hline Refused & $3 / 3$ & $3 / 5$ & $4 / 4$ \\
\hline
\end{tabular}

* significant at $\mathrm{P}<0.05 \quad * *$ significant at $\mathrm{P}<0.01$

Table 3: Influence of listening slow music or fast music on daily milk yield per buffalo cow (Mean \pm SE).

\begin{tabular}{|l|c|c|c|}
\hline \multicolumn{1}{|c|}{ Group } & Control & Slow music & Fast music \\
Body condition score & & & \\
\hline Moderate & $4.85 \pm 0.35^{\mathrm{a}}$ & $5.10 \pm 0.41^{\mathrm{b}}$ & $4.35 \pm 0.73^{\mathrm{c}}$ \\
\hline High & $9.75 \pm 1.25^{\mathrm{a}}$ & $10.42 \pm 1.32^{\mathrm{b}}$ & $8.63 \pm 1.51^{\mathrm{c}}$ \\
\hline LSD 0.05 & \multicolumn{3}{|c|}{0.22} \\
\hline LSD 0.01 & \multicolumn{3}{|c|}{0.39} \\
\hline
\end{tabular}

Values carrying different superscripts in the same row are significantly different $(\mathrm{P}<0.01)$.

Table 3 and figure 1 revealed that the daily milk yield of buffalo cows in slow music groups was significantly $(\mathrm{P}<0.05)$ higher than those in control ones which was in turn higher $(\mathrm{P}<0.05)$ than those in fast music groups. The daily milk yield in slow music groups (in moderate and high BCS) was $5 \%$ and $6.9 \%$, respectively higher than that of control groups. On the other hand, the daily milk yield in fast music groups (in moderate and high BCS) was $10.3 \%$ and $11.5 \%$, respectively lower than that of control groups.

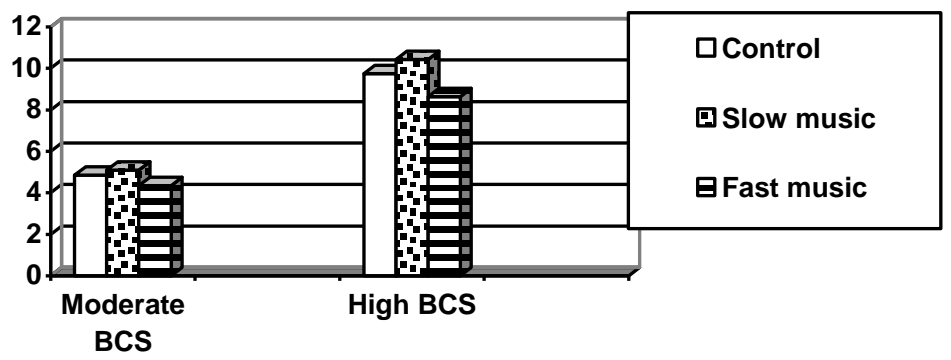

Fig. 1: Influence of listening slow music or fast music on daily milk yield per buffalo cow (Liter/day). 
Table 4: Influence of listening slow music or fast music on milk cortisol level in buffalo cows $(\mathrm{ng} / \mathrm{ml})$.

\begin{tabular}{|l|l|c|c|}
\hline Group & Control & Slow music & Fast music \\
Body condition score & & & \\
\hline Moderate & $0.37 \pm 0.06^{\mathrm{a}}$ & $0.30 \pm 0.04^{\mathrm{b}}$ & $0.45 \pm 0.03^{\mathrm{c}}$ \\
\hline High & $0.35 \pm 0.07^{\mathrm{a}}$ & $0.28 \pm 0.05^{\mathrm{b}}$ & $0.47 \pm 0.05^{\mathrm{c}}$ \\
\hline LSD 0.05 & \multicolumn{3}{|c|}{0.05} \\
\hline LSD 0.01 & \multicolumn{3}{|c|}{0.09} \\
\hline
\end{tabular}

Values carrying different superscripts in either rows or columns are significantly different $(\mathrm{P}<0.05)$.

Table 4 and figure 2 revealed that the milk cortisol of buffalo cows in slow music groups was significantly $(\mathrm{P}<0.05)$ lower than those in control ones which was in turn lower $(\mathrm{P}<0.05)$ than those in fast music groups. There were no significant differences between moderate and high BCS groups after listening either slow music or fast music.
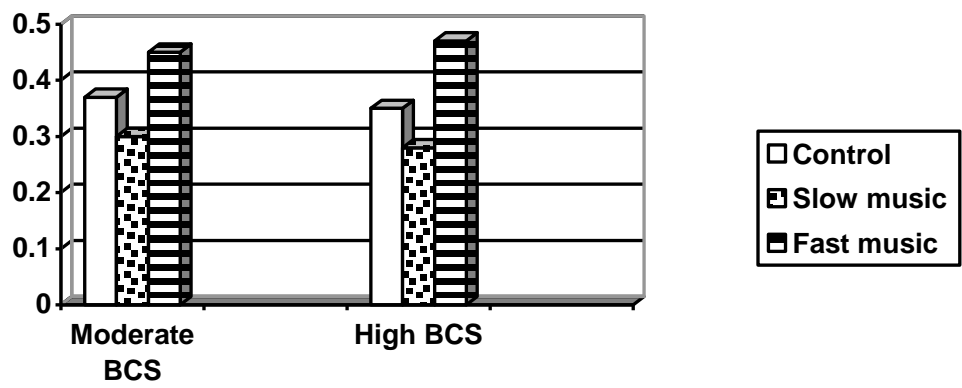

Fig. 2: Influence of listening slow music or fast music on milk cortisol level in buffalo cows $(\mathrm{ng} / \mathrm{ml})$.

\section{DISCUSSION}

Applied sound therapy for animals is not a new concept and dairy farmers have been playing it to their cows during milking for years, and much anecdotal and hard evidence exists proving that cows produce more milk if they have music played for them. Thus, music has been used successfully to reduce pain, depression, stress and anxiety (McCaffrey and Good, 2000; Hilliard, 2001 and Vickers and Cassileth, 2001), and is widely employed in institutional settings as an alternative form of therapy (Lipe, 1987 and Christie, 1992).

The present study revealed that during presenting of the slow music, all buffalo cows had a pronounced trend to spend more time 
displaying behaviors indicative of relaxation (no rumination) and standing still attentively and directed their ears toward the sound source. After presenting of the slow music, all mothers were psychologically and physically prepared to milking and spent less time showing behaviors typically associated with stress (latency till milking) than the control. On the other hand, presenting fast music increased the time spent in behaviors typically associated with stress (latency till milking) than the control and slow music groups. Furthermore, after listening of either slow music some of nervous buffalo cows responded and became easily manipulated than control group. Consequently, the buffalo cows became more calm and quiescent and had an improved mood and lower levels of stress. These results agree with those of Greenough, (1976), Anonymous, (1994) and Uetake et al. (1997).

Soothing noise is stimulating and relaxing for cows which caused them to increase their milk production (McCowan, et al., 2002). It has been found that slow music increased daily milk yield in cows by $3 \%$ (Nold, 2007). The relieve of stress and improvement of the buffalo cow welfare, observed in our study, has been reflected on the daily milk production. We found that the daily milk yield was significantly higher in slow music $(\mathrm{P}<0.05)$ group than that in control and fast music groups. Furthermore, the daily milk yield in high BCS groups was higher than that in moderate BCS groups in slow music treatment.

Generally, the cortisol level is considered as an indication of the stress state in animal. Our behavioral results indicated that the listening of slow music seems to affect positively the welfare and productive performance in buffalo cows. The behavioral change was coincided with the hormonal change and this may be attributed to the effect of auditory stimuli which had a relaxing effect on animal health. On the other hand, there were no significant differences between moderate and high BCS groups after listening either slow music or fast music because these auditory stimuli just change the mode of the animal. Milk cortisol level in the present study is consistent with that reported by Shutt and Fell, (1985).

\section{CONCLUSION}

It could be concluded that listening of slow music has a calming effect that reduces stress behavior and finally improves the milk production. In addition, the calming effect of slow music was more prominent in buffalo cows with high BCS than those with moderate BCS. On the other hand, the listening of fast music has a noising effect that increases stress and finally reduces milk production. 


\section{REFRERNCES}

Algers, B.; Ekesbo, I. and Sromberg, S. (1978): The impact of continous noise on animal health. Acta Vet. Scand. 19 (suppl. 67), 1-26.

Anonymous, (1994): Music good for chickens. World Poult. 10 (12), $7 .$.

Arave, C.W.; Bunch, T.D. and Callan, R.J. (1991): Measuring stress in cattle via implanted heart rate transmitters. J. Anim. Sci. 69, 236 (Abstract).

Bond, J.; Winchester, C.F.; Campbell, L.E. and Webb, J.C. (1963): Effects of loud sound on the physiology and behaviour of swine. Tech. Bull. Agric. Res. Serv. USAD. Washington DC, 1280, 1-17.

Brent, L. and Weaver, D. (1996): The physiological and behavioral effects of radio music on singly housed baboons. J. Med. Primatol. 25, 370-374.

Christie, M.E. (1992): Music therapy applications in a skilled and intermediate care nursing home facility: a clinical study. Act. Adapt. Aging 16, 69-87.

Cook, N.J.; Schaefer, A.L.; Lepage, P. and Morgan Jones, S. (1996): Salivary vs. serum cortisol for the assessment of adrenal activity in swine. Can. J. Anim. Sci. 76:329-335.

Elridge, G.A. (1988): Road transport factors that may influence stress in cattle. In: Proceedings of the Thirty-fourth International Congress of Meat Science and Technology, Brisbane, Queensland, pp. 148-149.

Forsling, M.L.; Sharman, D.F. and Stephens, D.B. (1984): Vasopressin in the blood plasma of pigs and calves exposed to noise and vibration comparable with that experienced during transport. J. Physiol. 3, 57-96.

Francesco, A.; Sartorelli, P.; Abdi, B.H. and Locateli, A. (1990): Effect of transport loading or noise on blood biochemical variables in calves. Am. J. Vet. Res. 51, 1679-1681.

Grandin, T. (1996): Factors that impede animal movement at slaughter plants. J. Am. Vet. Med. Assoc. 209, 757-759.

Greenough, W.T. (1976): Enduring brain effects of differential experience and training. Neural mechanisms of learning and memory. M.R. Rosenzweig and E.L. Bennett, ed. MIT Press, Cambridge, MA. PP. 225-278. 
Gyax, L.; Neuffer, I.; Kaufmann, C.; Hauser, R. and Wechsler, B. (2006): Milk cortisol concentaration in automatic milking systems compared with autotandem milking parlors. J. Dairy Science 89(9): 3447-54.

Hilliard, R.E. (2001): The effects of music therapy-based bereavement groups on mood and behavior of grieving children: a pilot study. J. Music Ther. 38, 291-306.

Howell, S.; Schwandt, M.; Fritz, J.; Roeder, E. and Nelson, C. (2003): A stereo music system as environmental enrichment for captive chimpanzees. Lab Anim. 32, 31-36.

Lipe, A.W. (1987): The use of music therapy as an individual activity. Act. Adapt. Aging 10, 93-102.

McCaffrey, R.G. and Good, M. (2000): The lived experience of listening to music while recovering from surgery. J. Holist. Nurs. 18, 378-390.

McCowan, B.; DiLorenzo, A.M.; Abichandani, S.; Brorelli, C. and Cullor, J.S. (2002): Bioacoustic tools for enhancing animal management and productivity: Effects of recorded calf vocalizations on milk production in dairy cows. Appl. Anim. Behav. Sci., 77, 13-20.

Melamed, S. and Bruhis, S. (1996): The effects of chronic industrial noise exposure on urinary cortisol, fatigue, and irritability. J. Occup. Med. 38, 252-256.

Minitab (1992): Statistical software, copyright 1992, release 8, MINITAB INC.

Molino, J.A. (1979): Annoyance and noise. In: Harris, C.M. (Ed.), Handbook of Noise Control. McGraw-Hill.

Möstl, E. and Palme, R. (2002): Hormones as indicators of stress. Domest. Anim. Endocrinol. 23:67-74.

Newberry, R.C. (1995): Environmental enrichment: Increasing the biological relevance of captive environments. Appl. Anim. Behav. Sci., 44, 229-243.

Nold, M.A. (2007): Well playing music and ffeding beer to cows cause them to produce more milk. Unpublished data, Depart. of Psychology, Missouri Western Stat University, USA.

O'Neill, P. (1989): A room with a view for captive primates: issues, goals, related research and strategies. In: Segal, E. (Ed.). Housing, Care and Psychological Well-Being of Captive and Laboratory Primates. Noyes Publications, NJ, pp. 135-160. 
Pacak, K. and Palkovits, M. (2001): Stressor specificity of central neuroendocrine responses: implications for stress-related disorders. Endocrinol. Rev. 22: 502-548.

Paul, M. and Patrick, B. (1986): Measuring behaviour. First edition. Cambridge University Press.

Sapolsky, R.M.; Romero, M.L. and Munck, A.U. (2000): How do glucocorticoids influence stress responses? Integrating permissive, suppressive, stimulatory, and preparative actions. Endocrinol. Rev. 21:55-89.

Shepherdson, D.; Bemment, N.; Carman, M. and Reynolds, S. (1989): Auditory enrichment for Lar gibbons hylobates lar at London Zoo. Int. Zoo Yrbk. 28, 256-260.

Shutt, D.A. and Fell, L.R. (1985): Comparison of total and free cortisol in bovine serum and milk or colostrums. J. Dairy Science, 68 (7): 1832-4.

Snedecor, G.W. and Cochran, W.G. (1980): Statistical Methods, seventh ed. Iowa State University Press. Ames, JA.

Spitzer, J.C. (1986): Influence of nutrition on reproduction in beef cattle. In Morrow, DA ( 2 nd ed.) Current Therapy in Ttheriogenology. W.B. Saunders, Philadelphia, pp. 320-341.

Stansley, J.M. (1986): Music research in medical/dental treatment: metaanalysis and clinical applications. J. Music Ther. 23, 56-122.

Stephens, D.B.; Bailey, K.J.; Sharman, D.F. and Ingram, D.L. (1985): An analysis of some behavioral effects of the vibration and noise components of transport in pigs. J.Exp. Physiol., 70, 211-217.

Talling, J.C.; Waran, N.K.; Wathes, C.M. and Lines, J.A. (1996): Behavioural and physiological responses of pigs to sound. Appli. Anim. Behav. Sci. 48, 187-201.

Talling, J.C.; Waran, N.K.; Wathes, C.M. and Lines, J.A. (1998): Sound avoidance by domestic pigs depends upon characteristics of the signal. Appli. Anim. Behav. Sci. 58, 225-266.

Uetake, K.; Hurnik, J.F. and Johnson, L. (1997): Effect of music on the voulntry approach of dairy cows to an automatic milking system. Appl. Anim. Behav. Sci. 58: 255-266.

Vickers, A.J. and Cassileh, B.R. (2001): Unconventional therapies for cancer and cancer-related symptoms. Lancet Oncol. 2, 226-232. 
Waynert, D.F.; Stookey, J.M.; Schwartzkopf-Genswein, K.S.; Watts, J.M. and Waltz, C.S. (1999): The responses of beef cattle to noise during handling. Appl. Anim. Behav. Sci. 62, 27-42. 